\title{
Prevalence of Etiological Agents and Antimicrobial Resistance Patterns of Bacterial Meningitis in Nemazee Hospital, Shiraz, Iran
}

\author{
Mohammad Motamedifar ${ }^{1,2}$; Hadi Sedigh Ebrahim-Saraie ${ }^{1, *} ;$ Davood Mansury $^{1} ;$ Iraj Nikokar $^{3}$; \\ Zahra Hashemizadeh ${ }^{4}$ \\ ${ }_{1}^{1}$ Department of Bacteriology and Virology, School of Medicine, Shiraz University of Medical Sciences, Shiraz, IR Iran \\ ${ }_{3}^{2}$ Shiraz HIV/AIDS Research Center, Shiraz University of Medical Sciences, Shiraz, IR Iran \\ ${ }_{3}^{3}$ Laboratory of Microbiology and Immunology of Infectious Diseases, Paramedicine Faculty, Guilan University of Medical Sciences, Rasht, IR Iran \\ 4 Professor Alborzi Clinical Microbiology Research Center, Shiraz University of Medical Sciences, Shiraz, IR Iran \\ ${ }^{*}$ Corresponding author: Hadi Sedigh Ebrahim-Saraie, Department of Bacteriology and Virology, School of Medicine, Shiraz University of Medical Sciences, Shiraz, IR Iran. Tel: \\ +98-9368829763, Fax: +98-7132304356, E-mail: Seddigh.hadi@gmail.com
}

Received: August 11, 2014; Revised: January 31, 2015; Accepted: February 24, 2015

\begin{abstract}
Background: Meningitis is a serious inflammation of the meninges, mainly caused by bacteria. Treatment of this life threatening disease should not be delayed; therefore, rapid empirical antibiotic therapy should be immediately started. Antimicrobial therapy based on early Cerebrospinal Fluid (CSF) examination has an important role in limitation of bacterial meningitis.

Objectives: The current study aimed to identify the prevalence of etiological agents of bacterial meningitis and their susceptibility patterns against commonly used antibiotics.

Patients and Methods: This cross-sectional study was performed within a two-year period 2011-2013 on all patients with suspected meningitis referring to Nemazee Hospital, Shiraz, Iran. Cerebrospinal fluid specimens were collected aseptically, and conventional methods were employed to isolate and identify the bacteria. Antimicrobial susceptibility tests were performed using disk diffusion method according clinical and laboratory standards institute (CLSI) recommendation.

Results: Out of 2229 suspected meningitis cases, 255 (11.4\%) were detected as positive culture. Most of the isolates were Gram-positive cocci, which 116 (45.5\%) were Staphylococcus epidermidis, and 20 (7.8\%) identified as Streptococcus spp. Among Gram-negative isolates, Escherichia coli and Acinetobacter spp., each with 19 isolates (5.9\%), were predominant. Overall, the most effective antibiotics against Gram-positive cocci were vancomycin (91.5\%), chloramphenicol (75.2\%), and gentamicin (59.3\%), respectively. Gram-negative isolates were mostly susceptible to gentamicin (65.1\%), chloramphenicol (42.9\%), and ciprofloxacin (39.7\%), respectively.

Conclusions: Gram-positive cocci, such as (Coagulase-Negative Staphylococci) CoNS and aerobic Gram-negative bacilli, were identified as the common etiologic agents of bacterial meningitis. Since the majority of these isolates was part of the normal flora and considered as opportunistic nosocomial infections, it is required to consider the importance of infection control programs in the healthcare centers.
\end{abstract}

Keywords: Bacterial Meningitis; Cerebrospinal Fluid; Nosocomial Infections

\section{Background}

The management of bacterial meningitis is still a priority of public health because of its rapid onset and high level of morbidity and mortality (1). Bacterial meningitis approximately causes more than one hundred thousand deaths per year worldwide (2). Meningitis continues to remain among the leading causes of childhood death, particularly in the developing countries (3). Nowadays in spite of the great improvement in modern antibiotics and healthcare services, the life-threatening problem of bacterial meningitis is not eliminated (4). Prolonged persistence of infection in the Cerebrospinal Fluid (CSF) may result in quite severe neurological dam- ages as well as mortality, if rapid measures are not taken (4). Rapid identification and immediate treatment of meningitis causative agent is necessary because of its potential devastating effects (5). Gram staining is widely available and as an inexpensive and rapid procedure is routinely performed for primary diagnosis of bacterial meningitis (6). However, gram staining sensitivity is not totally reliable, so CSF culture is mandatory to diagnose bacterial meningitis $(5,6)$. Implementation of rational antimicrobial therapy based on the findings of early CSF examination has an important role in limitation of bacterial meningitis and also its future outbreaks (5). Bac-

Copyright (C) 2015, Infectious Diseases and Tropical Medicine Research Center. This is an open-access article distributed under the terms of the Creative Commons Attribution-NonCommercial 4.0 International License (http://creativecommons.org/licenses/by-nc/4.0/) which permits copy and redistribute the material just in noncommercial usages, provided the original work is properly cited. 
terial meningitis often presents nonspecific signs and symptoms, especially in neonates; therefore, empirical antimicrobial therapy should be initiated based on low clinical suspicion until CSF culture results would be prepared (1). Empirical antibiotic treatment is advised in cases of suspected meningococcal disease, depends on local resistance patterns and the medical environment (4). But, because of the selective pressure, extensive empirical uses of broad-spectrum antibiotics often lead to the emergence of resistant isolates against many antimicrobial agents (7). New information of antimicrobial susceptibility testing for routinely used antibiotics could guide clinicians to better choices of antibiotics for prophylaxis purposes $(2,8)$. Antibiotic susceptibility patterns may also vary among hospitals; therefore, this information is particularly vital for the effectiveness of empirical therapy in acute cases $(7,9)$. Neisseria meningitides, Streptococcus pneumonia, and Haemophilus influenzae type b are most commonly associated with bacterial meningitis (5). However, the relative prevalence of the reported bacterial meningitis isolates vary with age and geographical regions (10). To the authors' best knowledge there is a lack of published reports on the analysis of bacterial meningitis in suspected patients and determination of antibacterial susceptibility patterns, especially in all the patients ranging neonates to adults the studied region. Such studies could indicate appropriate therapy of bacterial meningitis, reduce the length of hospitalization and decrease the relative morbidity and mortality rate. Besides, information on such a regional study might be extended to the rest of the world.

\section{Objectives}

The current study aimed to determine the prevalence of etiologic bacteria and their susceptibility patterns against commonly used antibiotics in Nemazee Teaching Hospital, Shiraz, Iran.

\section{Patients and Methods}

\subsection{Study Area and Subjects}

This descriptive cross-sectional study was conducted within two years from March 2011 to February 2013. All patients with suspected meningitis who referred to Nemazee Teaching Hospital, affiliated to Shiraz University of Medical Sciences, were included. Nemazee Hospital is a major tertiary care hospital in South-West of Iran with one thousand beds. Totally, 2229 CSF samples were collected during the study period. The patients were categorized into three groups: neonatal and children up to two years old, children aged 2-14 years, and another group including all the patients older than 14 years. There was no age limit in the inclusion criteria and just suspecting to meningitis based on compatible clinical manifestations (fever, headache, and neck stiffness) by the physician was examined. Bacterial meningitis was confirmed by CSF positive cultures. Exclusion criteria were taking antibiotic 24 hours before admission to the hospital.

\subsection{Specimens and Bacterial Identification}

Cerebrospinal fluid specimens were collected aseptically by lumbar puncture at the discretion of the attending physicians and transferred into sterile tubes. Clinical specimens were sent to microbiology laboratory within 20 minutes. Conventional bacteriological methods were employed to isolate and identify the bacteria. Cerebrospinal fluid specimens were seeded on to cultures media, blood agar, chocolate agar and thioglycolate enrichment broth (Merck, Germany), for 48 hours incubation in humid air plus $5-10 \% \mathrm{CO}_{2}$.

\subsection{Antimicrobial Susceptibility Testing}

Susceptibility profiles were determined by following locally available antibiotics using disk diffusion method according to clinical and laboratory standards institute (CLSI) recommendation (11). Antimicrobial disks (Mast, UK) used for Gram-positive isolates included ampicillin $(10 \mu \mathrm{g})$, vancomycin $(30 \mu \mathrm{g})$, erythromycin $(15 \mu \mathrm{g})$, cotrimoxazole $(25 \mu \mathrm{g})$, chloramphenicol $(30 \mu \mathrm{g})$, gentamicin $(10 \mu \mathrm{g})$, lincomycin $(2 \mu \mathrm{g})$, ciprofloxacin $(5$ $\mu \mathrm{g})$, cephalexin $(30 \mu \mathrm{g})$, cloxacillin $(1 \mu \mathrm{g})$, ofloxacin (5 $\mu \mathrm{g})$, and azithromycin $(15 \mu \mathrm{g})$. In addition, amikacin (30 $\mu \mathrm{g})$, ceftizoxime (30 $\mu \mathrm{g})$, and cefixime (5 $\mu \mathrm{g})$ disks (Mast, UK) were also considered for the Gram-negative isolates. The test was performed on Mueller-Hinton agar (Merck, Germany). Statistical analysis of the infectious agents and antimicrobial susceptibility frequency were performed using SPSS software version 19. The results were presented as descriptive statistics in terms of relative frequency.

\section{Results}

From a total of 2229 CSF specimens obtained from suspected meningitis cases, 255 (11.4\%) samples were detected as bacterial culture positive. Out of the 255 positive cases, 137 (53.7\%) belonged to males and the remaining 118 (46.3\%) belonged to females. The mean age of the patients was $34 \pm 26$ years and the age range was from 1 month to 93 years. The majority of positive cases $(179=70.2 \%)$ belonged to patients older than 14 years . The common bacterial isolates were Gram-positive cocci, which Staphylococcus epidermidis with 116 (45.5\%) and Streptococcus spp. with 20 (7.8\%) isolates were on the top, respectively. Among Gram-negative isolates, Escherichia coli and Acinetobacter spp., each with the frequency of 19 (5.9\%) species, were predominant. S. epider- 
midis $(\mathrm{n}=18)$ and Klebsiella spp. $(\mathrm{n}=2)$ were the most prevalent Gram-positive and Gram-negative isolates from neonates and children aged less than two years. For the children with an age range of 2-14 years, S. epidermidis $(\mathrm{n}=20)$ and Pseudomonas spp. $(\mathrm{n}=4)$ were the most prevalent ones. S. epidermidis $(\mathrm{n}=78)$ and $E$. coli $(n=12)$ were mostly isolated from the adult patients. The age and isolate distribution patterns of the studied subjects are summarized in Table 1. Antibacterial susceptibility tests revealed that the highest resistance rates in Gram-positive isolates were observed against cloxacillin (81.3\%), erythromycin (70.1\%), and cephalexin (62.1\%), respectively. On the other hand, the most effective antibiotics against Gram-positive cocci were vancomycin (91.5\%), chloramphenicol (75.2\%), and gentamicin (59.3\%), respectively. Enterococcus spp., as the most resistant isolates among Gram-positive cocci, showed the highest sensitivity to vancomycin. Among the Gram-negative isolates, the highest resistance rates were observed against tetracycline (98.4\%), cefixime (95.2\%), and cephalexin (92.1\%), respectively. The most susceptibility rates in Gram-negative isolates belonged to gentamicin (65.1\%), chloramphenicol (42.9\%), and ciprofloxacin (39.7\%), respectively. Few isolates of Acinetobacter spp., as the most resistant Gram-negative iso- lates, were only sensitive to gentamicin, amikacin, and chloramphenicol. The results of antibiotic susceptibility patterns for Gram-positive and -negative isolates are presented in Tables 2 and 3, respectively.

\section{Discussion}

Since an exact etiological diagnosis of the pathogen is not immediately available in the infectious diseases, the primary choice of antibiotics is usually empirical (4). Meningitis without appropriate therapy is usually fatal (1). Previously, in a seven-year study by MosaviJarrahi et al. meningitis fatality rate was reported $4.5 \%$ for Iran (12). Microbiological identification and susceptibility testing of the causative agents are the key to select effective antibiotic therapy (1). Identifying the most prevalent organisms causing bacterial meningitis and their susceptibility patterns are usually studied in children, but rarely in adults. The current study included patients aged one month to 93 years old and categorized them in three groups. Bacterial isolation rate from CSF samples was $11.4 \%$ in the present study; previous isolation rates in Iran were reported with various ranges. Yousefi Mashouf et al. reported a rate of $25.1 \%$ in children aged less than 10 years old from Hamadan (13).

Table 1. The Distribution of Recovered Bacterial Isolates Based on the Patients' Age ${ }^{\text {a }}$

\begin{tabular}{|c|c|c|c|c|}
\hline \multirow[t]{2}{*}{ Isolates } & \multicolumn{4}{|c|}{ Patients' Age } \\
\hline & $\leq \mathbf{2}$ & $2-14$ & $\geq 14$ & Total, No. (\%) \\
\hline Staphylococcus epidermidis & 18 & 20 & 78 & $116(45.5)$ \\
\hline Streptococcus spp. & 3 & 3 & 14 & $20(7.8)$ \\
\hline CoNS & 1 & 1 & 15 & $17(6.7)$ \\
\hline Staphylococcus aureus & 1 & 1 & 13 & $15(5.9)$ \\
\hline Escherichia coli & 1 & 2 & 12 & $15(5.9)$ \\
\hline Acinetobacter spp. & 1 & 3 & 11 & $15(5.9)$ \\
\hline Klebsiella spp. & 2 & 1 & 11 & $14(5.5)$ \\
\hline Enterococcus spp. & 2 & 2 & 6 & $10(3.9)$ \\
\hline Pseudomonas spp. & 1 & 4 & 5 & $10(3.9)$ \\
\hline Enterobacter spp. & 0 & 3 & 6 & $9(3.5)$ \\
\hline Diphtheroids & 1 & 4 & 4 & $9(3.5)$ \\
\hline Bacillus spp. & 1 & 0 & 3 & $4(1.6)$ \\
\hline Proteus spp. & 0 & 0 & 1 & $1(0.4)$ \\
\hline Total, No. (\%) & $32(12.5)$ & $44(17.3)$ & $179(70.2)$ & $255(100)$ \\
\hline
\end{tabular}

a Abbreviation: CoNS, Coagulase-negative Staphylococcus (CoNS). 
Motamedifar M et al.

\begin{tabular}{|c|c|c|c|c|c|}
\hline Antibiotics & $\begin{array}{l}\text { Staphylococcus } \\
\text { aureus }(\mathbf{n}=\mathbf{1 5})\end{array}$ & $\begin{array}{c}\text { Enterococcus spp. } \\
(\mathbf{n}=\mathbf{1 0})\end{array}$ & $\begin{array}{c}\text { Streptococcus spp. } \\
(\mathbf{n}=\mathbf{2 0})\end{array}$ & $\begin{array}{l}\text { CoNS } \\
(\mathrm{n}=17)\end{array}$ & $\begin{array}{c}\text { Staphylococcus epi- } \\
\text { dermidis }(\mathbf{n}=\mathbf{1 1 6})\end{array}$ \\
\hline \multicolumn{6}{|l|}{ Cloxacillin } \\
\hline $\mathrm{R}$ & $11(73.3)$ & $10(100)$ & $15(75)$ & $13(76.5)$ & $91(78.5)$ \\
\hline I & 0 & 0 & 0 & 0 & $4(3.4)$ \\
\hline$S$ & $4(26.7)$ & 0 & $5(25)$ & $4(23.5)$ & $21(18.1)$ \\
\hline \multicolumn{6}{|l|}{ Lincomycin } \\
\hline $\mathrm{R}$ & $8(53.3)$ & $10(100)$ & $11(55)$ & $11(64.7)$ & $60(51.7)$ \\
\hline I & 0 & 0 & $1(5)$ & 0 & $3(2.6)$ \\
\hline$S$ & $7(46.7)$ & 0 & $8(40)$ & $6(35.3)$ & $53(45.7)$ \\
\hline \multicolumn{6}{|c|}{ Chloramphenicol } \\
\hline $\mathrm{R}$ & 0 & $2(20)$ & $6(30)$ & $3(17.6)$ & $15(12.9)$ \\
\hline I & $2(13.3)$ & $6(60)$ & $5(25)$ & 0 & $5(4.3)$ \\
\hline$S$ & $13(86.7)$ & $2(20)$ & $9(45)$ & $14(82.3)$ & $96(82.8)$ \\
\hline \multicolumn{6}{|l|}{ Vancomycin } \\
\hline $\mathrm{R}$ & 0 & $6(60)$ & $8(40)$ & 0 & 0 \\
\hline I & 0 & $1(10)$ & 0 & 0 & 0 \\
\hline S & $15(100)$ & $3(30)$ & $12(60)$ & $17(100)$ & $116(100)$ \\
\hline \multicolumn{6}{|c|}{ Co-trimoxazole } \\
\hline $\mathrm{R}$ & $1(6.7)$ & $10(100)$ & $18(90)$ & $12(70.6)$ & $51(44)$ \\
\hline I & $2(13.3)$ & 0 & 0 & 0 & $5(4.3)$ \\
\hline$S$ & $12(80)$ & 0 & $2(10)$ & $5(29.4)$ & $60(51.7)$ \\
\hline \multicolumn{6}{|c|}{ Ciprofloxacin } \\
\hline $\mathrm{R}$ & $9(60)$ & $8(80)$ & $10(50)$ & $12(70.6)$ & $43(37)$ \\
\hline I & $1(6.7)$ & $2(20)$ & $2(10)$ & 0 & $2(1.8)$ \\
\hline S & $5(33.3)$ & 0 & $8(40)$ & $5(29.4)$ & $71(61.2)$ \\
\hline \multicolumn{6}{|c|}{ Erythromycin } \\
\hline $\mathrm{R}$ & $10(66.7)$ & $9(90)$ & $14(70)$ & $13(76.5)$ & $77(66.4)$ \\
\hline I & 0 & $1(10)$ & 0 & 0 & $1(0.9)$ \\
\hline S & $5(33.3)$ & 0 & $6(30)$ & $4(23.5)$ & $38(32.7)$ \\
\hline \multicolumn{6}{|l|}{ Gentamicin } \\
\hline $\mathrm{R}$ & $6(40)$ & $9(90)$ & $12(60)$ & $5(29.4)$ & $30(25.9)$ \\
\hline I & $1(6.7)$ & $1(10)$ & $2(10)$ & $2(11.8)$ & $4(3.4)$ \\
\hline S & $8(53.3)$ & 0 & $6(30)$ & $10(58.8)$ & $82(70.7)$ \\
\hline \multicolumn{6}{|l|}{ Cephalexin } \\
\hline $\mathrm{R}$ & $8(53.3)$ & $10(100)$ & $15(75)$ & $13(76.5)$ & $57(49.1)$ \\
\hline I & $1(6.7)$ & 0 & 0 & 0 & $6(5.2)$ \\
\hline S & $6(40)$ & 0 & $5(25)$ & $4(23.5)$ & $53(45.7)$ \\
\hline \multicolumn{6}{|l|}{ Ofloxacin } \\
\hline $\mathrm{R}$ & - & $8(80)$ & $12(60)$ & - & - \\
\hline I & - & $2(20)$ & $2(10)$ & - & - \\
\hline S & - & 0 & $6(30)$ & - & - \\
\hline \multicolumn{6}{|c|}{ Azithromycin } \\
\hline $\mathrm{R}$ & - & $10(100)$ & $15(75)$ & - & - \\
\hline I & - & 0 & 0 & - & - \\
\hline S & - & 0 & $5(25)$ & - & - \\
\hline \multicolumn{6}{|l|}{ Ampicillin } \\
\hline $\mathrm{R}$ & - & $10(100)$ & $10(100)$ & - & - \\
\hline I & - & 0 & 0 & - & - \\
\hline$S$ & - & 0 & 0 & - & - \\
\hline
\end{tabular}




\begin{tabular}{|c|c|c|c|c|c|}
\hline Antibiotics & $\begin{array}{l}\text { Acinetobacter spp. } \\
(\mathbf{n}=\mathbf{1 5})\end{array}$ & $\begin{array}{c}\text { E. coli } \\
(\mathbf{n}=\mathbf{1 5})\end{array}$ & $\begin{array}{l}\text { Enterobacter } \mathbf{s p p} . \\
\quad(\mathbf{n}=\mathbf{9})\end{array}$ & $\begin{array}{l}\text { Klebsiella spp. } \\
\quad(\mathbf{n}=\mathbf{1 4})\end{array}$ & $\begin{array}{l}\text { Pseudomonas spp. } \\
(\mathbf{n}=\mathbf{1 0})\end{array}$ \\
\hline \multicolumn{6}{|l|}{ Ceftizoxime } \\
\hline $\mathrm{R}$ & $15(100)$ & $13(86.7)$ & $7(77.8)$ & $12(85.7)$ & $10(100)$ \\
\hline I & 0 & 0 & 0 & 0 & 0 \\
\hline S & 0 & $2(13.3)$ & $2(22.2)$ & $2(14.3)$ & 0 \\
\hline \multicolumn{6}{|l|}{ Tetracycline } \\
\hline $\mathrm{R}$ & $15(100)$ & $12(80)$ & $8(88.9)$ & $14(100)$ & $10(100)$ \\
\hline I & 0 & $2(13.3)$ & $1(11.1)$ & 0 & 0 \\
\hline S & 0 & $1(6.7)$ & 0 & 0 & 0 \\
\hline \multicolumn{6}{|l|}{ Amikacin } \\
\hline $\mathrm{R}$ & $14(93.3)$ & $2(13.3)$ & $2(22.2)$ & $5(35.7)$ & $5(50)$ \\
\hline I & 0 & $7(46.7)$ & $1(11.1)$ & $1(7.1)$ & $2(20)$ \\
\hline S & $1(6.7)$ & $6(40)$ & $6(66.7)$ & $8(57.2)$ & $3(30)$ \\
\hline \multicolumn{6}{|c|}{ Chloramphenicol } \\
\hline $\mathrm{R}$ & $14(93.3)$ & 0 & $3(33.3)$ & $7(50)$ & $10(100)$ \\
\hline I & 0 & 0 & $1(11.1)$ & $1(7.1)$ & 0 \\
\hline$S$ & $1(6.7)$ & $15(100)$ & $5(55.6)$ & $6(42.9)$ & 0 \\
\hline \multicolumn{6}{|c|}{ Ciprofloxacin } \\
\hline $\mathrm{R}$ & $12(80)$ & $6(40)$ & $5(55.6)$ & $10(71.5)$ & $4(40)$ \\
\hline I & 0 & 0 & 0 & $1(7.1)$ & 0 \\
\hline S & $3(20)$ & $9(60)$ & $4(44.4)$ & $3(21.4)$ & $6(60)$ \\
\hline \multicolumn{6}{|l|}{ Gentamicin } \\
\hline $\mathrm{R}$ & $1(6.7)$ & $4(26.7)$ & $2(22.2)$ & $10(71.5)$ & $2(20)$ \\
\hline I & 0 & 0 & 0 & $1(7.1)$ & $2(20)$ \\
\hline$S$ & $14(93.3)$ & $11(73.3)$ & $7(77.8)$ & $3(21.4)$ & $6(60)$ \\
\hline \multicolumn{6}{|l|}{ Cefixime } \\
\hline $\mathrm{R}$ & $15(100)$ & $15(100)$ & $7(77.8)$ & $12(85.7)$ & $10(100)$ \\
\hline I & 0 & 0 & $1(11.1)$ & 0 & 0 \\
\hline$S$ & 0 & 0 & $1(11.1)$ & $2(14.3)$ & 0 \\
\hline \multicolumn{6}{|l|}{ Cephalexin } \\
\hline $\mathrm{R}$ & $15(100)$ & $13(86.7)$ & $8(88.9)$ & $12(85.7)$ & $10(100)$ \\
\hline I & 0 & 0 & 0 & 0 & 0 \\
\hline$S$ & 0 & $2(13.3)$ & $1(11.1)$ & $2(14.3)$ & 0 \\
\hline \multicolumn{6}{|c|}{ Co-trimoxazole } \\
\hline $\mathrm{R}$ & $15(100)$ & $4(26.7)$ & $5(55.6)$ & $9(64.3)$ & $10(100)$ \\
\hline I & 0 & 0 & $1(11.1)$ & 0 & 0 \\
\hline$S$ & 0 & $11(73.3)$ & $3(33.3)$ & $5(35.7)$ & 0 \\
\hline
\end{tabular}

Also in a ten-year retrospective study by Rezaeizadeh et al. (14) the rate was reported $2.9 \%$ in Tehran; and Ghotaslou et al. (15) reported culture positive rate of 3.9\% in Children Hospital of Tabriz. Thomas et al. determined this rate as $10.6 \%$ in children suspected to meningitis in Royal Hospital of Oman (16). In similar studies from two African countries, Namibia and Ethiopia, reported frequencies are $9.6 \%$ and $5.6 \%$, respectively $(17,18)$. This may be a reflection of the different infection control policies and other factors involved in the mentioned regions or countries (19). In the current study, the most common bacteria causing meningitis was S. epidermidis 
(45.5\%). CoNS, especially S. epidermidis, are considered as the main cause of nosocomial infections in the pediatric age groups; while they are commonly considered as the contamination in adult samples. However, ventriculoperitoneal shunt infections by these bacteria are a common complication in patients with these devices even in adults (20). It is in agreement with the results of a previous study from Iran by Shayanfar et al. (21). Also the results from repeated cultures and the similar isolation rates in other studies would reject the possibility of contamination of specimens. However, final approval for bacterial meningitis caused by CoNS was accompanied with the results of CSF examination (glucose and protein level) to differentiate from asymptomatic meningitis (22). Although N. meningitides, S. pneumonia and $H$. influenzae type b are the most common causes of bacterial meningitis, based on the previous reports from the Iranian studies, patterns seem to be different from other parts of the world. While Yousefi Mashouf et al. form Hamadan, Iran, introduced S. pneumonia as the most common isolate (13), Rezaeizadeh et al. (14) in Tehran and Japoni et al. (7) in Shiraz introduced coagulase-negative Staphylococcus (CoNS) species as the most prevalent causative agents of bacterial meningitis with a frequency of $40.1 \%$ and $36.3 \%$, respectively; as the closest rates to the current study findings. Also, Bahador et al. (23) in Kerman and Ghotaslou et al. (15) in Tabriz reported $N$. meningitides, S. pneumonia and $H$. influenza as the most common bacteria isolated from the Iranian patients with meningitis. Gram-positive cocci as the causative agent of bacterial meningitis was almost confirmed in all the previous studies from Iran, which was in agreement with the findings of the current study; but Aletayeb et al. (24) reported Klebsiella pneumoniae and Enterobacter spp. as the two main causative agents of neonatal bacterial meningitis form Emam Khomeini Hospital in Ahvaz, Iran. Although Klebsiella spp. was the most frequent Gram-negative isolate among children younger than two years, in the current study it was not the most prevalent causative agent of meningitis in these patients. Abdinia et al. (25) and Yousefi Mashouf et al. (13) reported S. pneumonia as the most common causative agent of bacterial meningitis among the Iranian pediatric patients in Tabriz and Hamadan. It is in not in agreement with the findings of the current study in which S. epidermidis was the predominant isolate. Similar finding reported from Oman and Yemen specified S. pneumonia as the most common pathogen among neonates $(16,26)$. In Ethiopia, $N$. meningitides was reported as the most common isolate among neonates and young children, and S. pneumonia, as the leading causes of bacterial meningitis in the adults groups, in a one-year hospital survey (17). All these reports highlight the variable nature of etiological agents of bacterial meningitis. According to the current study, with increasing age in the studied groups, bacterial isolation rates also increased, which was similar to the findings of Domingo et al. from Spain indicating that the elderly patients are at a much higher risk of developing bacterial meningitis than younger adults (27). Overall in the present study, gentamicin, as an aminoglycoside, was one of the best choices for Gram-positive and -negative isolates with $59.3 \%$ and $65.1 \%$ sensitivity, respectively, which was in agreement with the report of Shayanfar et al. in Tehran (21). However in a previous study by Rezaeizadeh et al. (14), Gram-negative isolates showed more sensitivity to amikacin in comparison with gentamicin. Although they reported Gram-positive susceptibility patterns almost same as those of the current study, and their Enterococcus spp. isolates were more sensitive to the tested antibacterial agents than the isolates of the current study. Although the results of the study by Japoni et al. (7) were not specific for CSF samples, a previous study in Shiraz provided good information on the susceptibility patterns of species isolated from CSF cultures. Overall, it seems that the Gram-positive isolates of the current study were more sensitive to co-trimoxazole and ciprofloxacin than the isolates in that of the Japoni et al. (7). Vancomycin resistance in Gram-positive cocci of the current study was more than that of Japoni et al.'s with less than $10 \%$. They evaluated the susceptibility of the isolates by determining the minimum inhibitory concentration (MIC) by E-test (7) as a more precise test than disk diffusion method, which was a limitation of the current study. Finally, based on the current study results, nosocomial meningitis was prevalent in the studied hospital. Opportunistic organisms, such as CoNS and aerobic Gram-negative bacilli, were considered as the common causes of nosocomial meningitis in the hospitalized patients. The prevention and control of nosocomial bacterial meningitis need serious attention, since the majority of diseases are caused by multidrugresistant pathogens (28). The results of the current study provide useful information to prescribe more effective empirical therapy and optimize institutional infection control policies. Therefore, the variable nature of etiological agents and antimicrobial susceptibility patterns of bacterial meningitis made it reasonable to provide continuous future updates on local resistance patterns of the most frequent bacterial pathogens associated with meningitis.

\section{Acknowledgements}

Authors wish to thank all the personnel at the Nemazee Hospital Microbiology laboratory for their technical assistance.

\section{Funding/Support}

This work was financially supported by Shiraz University of Medical Sciences grant No. 5336.

\section{References}

1. Brouwer MC, Tunkel AR, van de Beek D. Epidemiology, diagnosis, 


\section{Motamedifar M et al.}

and antimicrobial treatment of acute bacterial meningitis. Clin Microbiol Rev. 2010;23(3):467-92.

2. Tzanakaki G, Mastrantonio P. Aetiology of bacterial meningitis and resistance to antibiotics of causative pathogens in Europe and in the Mediterranean region. Int J Antimicrob Agents. 2007;29(6):621-9.

3. Mahmoudi S, Zandi H, Pourakbari B, Ashtiani MT, Mamishi S. Acute bacterial meningitis among children admitted into an Iranian referral children's hospital. Jpn J Infect Dis. 2013;66(6):503-6.

4. Hoffman O, Weber RJ. Pathophysiology and treatment of bacterial meningitis. Ther Adv Neurol Disord. 2009;2(6):1-7.

5. Alam MR, Saha SK, Nasreen T, Latif F, Rahman SR, Gomes DJ. Detection, antimicrobial susceptibility and serotyping of Streptococcus pneumoniae from cerebrospinal fluid specimens from suspected meningitis patients. Banglad J Microbiol. 2007;24(1):24-9.

6. Wu HM, Cordeiro SM, Harcourt BH, Carvalho M, Azevedo J, Oliveira TQ, et al. Accuracy of real-time PCR, Gram stain and culture for Streptococcus pneumoniae, Neisseria meningitidis and Haemophilus influenzae meningitis diagnosis. BMC Infect Dis. 2013;13:26.

7. Japoni A, Vazin A, Hamedi M, Davarpanah MA, Alborzi A, Rafaatpour N. Multidrug-resistant bacteria isolated from intensivecare-unit patient samples. Braz I Infect Dis. 2009;13(2):118-22.

8. Nikokar I, Tishayar A, Flakiyan Z, Alijani K, Rehana-Banisaeed S, Hossinpour M, et al. Antibiotic resistance and frequency of class 1 integrons among Pseudomonas aeruginosa, isolated from burn patients in Guilan, Iran. Iran J Microbiol. 2013;5(1):36-41.

9. Motamedifar M, Sarai HSE, Mansury D. Patterns of Constitutive and Inducible Clindamycin Resistance in Staphylococcus aureus Isolated from Clinical Samples by D-test Method, Shiraz, Southwest of Iran. Galen Med J. 2014;3(4):216-21.

10. Modi S, Anand AK. Phenotypic Characterization and Antibiogram of CSF Isolates in Acute Bacterial Meningitis. J Clin Diagn Res. 2013;7(12):2704-8.

11. Clinical and Laboratory Standards Institute.. Performance Standards for Antimicrobial Susceptibility Testing; 21th Informational Supplement M100-S21.Wayne, PA: CLSI; 2011.

12. Mosavi-Jarrahi A, Esteghamati A, Asgari F, Heidarnia M, MousaviJarrahi Y, Goya M. Temporal analysis of the incidence of meningitis in the Tehran metropolitan area,1999-2005. Popul Health Metr. 2009;7:19.

13. Yousefi Mashouf R, Hashemi SH, Bijarchi M. Bacterial Agents of Meningitis in Children and Detection of Their Antibiotic Resistance Patterns in Hamadan, Western Iran. Pak J Bio Sci. 2006;9(7):1293-8.

14. Rezaeizadeh G, Pourakbari B, Ashtiani MH, Asgari F, Mahmoudi S, Mamishi S. Antimicrobial susceptibility of bacteria isolated from cerebrospinal fluids in an Iranian referral pediatric center,
1998-2008. Maedica (Buchar). 2012;7(2):131-7.

15. Ghotaslou R, Farajnia S, Yeganeh F, Abdoli-Oskouei S, Ahangarzadeh Rezaee M, Barzegar M. Detection of acute childhood meningitis by PCR, culture and agglutination tests in Tabriz, Iran. Acta Med Iran. 2012;50(3):192-6.

16. Thomas V, Ahmed R, Qasim S. Cerebro spinal fluid analysis in childhood bacterial meningitis. Oman Med J. 2008;23(1):32-3.

17. Mulu A, Moges F, Tessema B, Kassu A. Pattern and multiple drug resistance of bacterial pathogens isolated from wound infection at University of Gondar Teaching Hospital, Northwest Ethiopia. Ethiop Med J. 2006;44(2):125-31.

18. Mengistu A, Gaeseb J, Uaaka G, Ndjavera C, Kambyambya K, Indongo L, et al. Antimicrobial sensitivity patterns of cerebrospinal fluid (CSF) isolates in Namibia: implications for empirical antibiotic treatment of meningitis. J Pharm Policy Pract. 2013;6:4.

19. Hoseini Alfatemi SM, Motamedifar M, Hadi N, Sedigh Ebrahim Saraie $\mathrm{H}$. Analysis of Virulence Genes Among Methicillin Resistant Staphylococcus aureus (MRSA) Strains. Jundishapur J Microbiol. $2014 ; 7(6)$.

20. Wells DL, Allen JM. Ventriculoperitoneal shunt infections in adult patients. AACN Adv Crit Care. 2013;24(1):6-12.

21. Shayanfar N, Mohammadpour M, Haghi-Ashtiani MT, Nejat F, Farahani NN, Abedini M, et al. Invasive bacteria isolates from children with cerebral shunt and pattern of antimicrobial drug susceptibility in an Iranian referral pediatrics center. Braz J Infect Dis. 2011;15(4):401-3.

22. Mamishi S, Rahimi P, Sohrabi A, Sabuni F, Edalat R, Mostafavi E, et al. Direct serotyping of enteroviruses in cerebrospinal fluid from children with aseptic meningitis. Jundishapur J Microbiol. 2013;6(9):ee7852.

23. Bahador M, Amini M, Bahador M. Common cause and cerebrospinal fluid changes of acute bacterial meningitis. Iran J Pathol. 2009;4(2):75-9.

24. Aletayeb MH, Ahmad FS, Masood D. Eleven-year study of causes of neonatal bacterial meningitis in Ahvaz, Iran. Pediatr Int. 2010;52(3):463-6.

25. Abdinia B, Ahangarzadeh Rezaee M, Abdoli Oskouie S. Etiology and antimicrobial resistance patterns of acute bacterial meningitis in children: a 10-year referral hospital-based study in northwest iran. Iran Red Crescent Med J. 2014;16(7).

26. Al Khorasani A, Banajeh S. Bacterial profile and clinical outcome of childhood meningitis in rural Yemen: a 2-year hospital-based study. J Infect. 2006;53(4):228-34.

27. Domingo P, Pomar V, de Benito N, Coll P. The spectrum of acute bacterial meningitis in elderly patients. BMC Infect Dis. 2013;13:108

28. van de Beek D, Drake JM, Tunkel AR. Nosocomial bacterial meningitis. N Engl J Med.2010;362(2):146-54. 